\title{
RAYLEIGH WAVE AND WELL HEAD RESPONSE TO CALCULATE POROSITY IN THE EDWARDS AQUIFER OF SOUTH-CENTRAL TEXAS, USA
}

\section{UPORABA RAYLEIGHJEVIH VALOV IN ODZIVA VODOSTAJEV V VODNJAKIH ZA IZRAČUN POROZNOSTI KAMNINE V EDWARDSOVEM VODONOSNIKU, JUŽNI IN OSREDNJI TEKSAS, ZDA}

\author{
Guangquan $\mathrm{LI}^{1}$, Yunpeng ZHANG ${ }^{2}$, Geary M. SCHINDEL ${ }^{3, *}$, \\ Malcolm S. FIELD ${ }^{4} \&$ Nico GOLDSCHEIDER ${ }^{5}$
}

\begin{abstract}
UDC 556.33:539.217(736.4)

Guangquan Li, Yunpeng Zhang, Geary M. Schindel, Malcolm S. Field \& Nico Goldscheider: Rayleigh wave and well head response to calculate porosity in the Edwards aquifer of southcentral Texas, USA

We use the magnitude and centroid period of Rayleigh wave along with the amplitude of fluctuations of water level in a well to calculate effective porosity of a karst aquifer at the site scale. The radial and vertical displacements of Rayleigh wave are first related to the confining pressure of rock, which is then related to fluid pressure via the Gassmann equation. Three seismograms recorded at station 633A of the USARRAY and the induced responses of Well J-17 in the Edwards Aquifer (Texas) allow the calculation of an effective porosity between 17.0 and 24.4 percent, the average of which is close to the total porosity of core samples determined by geophysical well logs. This paper provides an innovative method to measure effective porosity in aquifers. Because of the long wavelengths of Rayleigh wave, the interdisciplinary approach is advantageous in that the resulting effective porosity is at the site scale which includes large conduits or voids.
\end{abstract}

Key words: Rayleigh wave, Poisson's ratio, displacements, well head, Gassmann equation.
Izvleček UDK 556.33:539.217(736.4)

Guangquan Li, Yunpeng Zhang, Geary M. Schindel, Malcolm S. Fielde Nico Goldscheider: Uporaba Rayleighjevih valov in odziva vodostajev $v$ vodnjakih za izračun poroznosti kamnine $v$ Edwardsovem vodonosniku, južni in osrednji Teksas, ZDA

Za izračun efektivne poroznosti kraškega vodonosnika na lokalni ravni smo uporabili velikost in centroidno časovno vrednost Rayleighjevega valovanja, skupaj $\mathrm{z}$ amplitudo nihanja vodne gladine v vrtini. Radialni in vertikalni premiki Rayleighjevega valovanja so najprej povezani s tlakom neprepustne kamnine, ki je nato z Gassmannovo enačbo povezan s tlakom tekočine. Trije seizmogrami, evidentirani na postaji 633A USARRAY, in inducirani odzivi vrtine J-17 v vodonosniku Edwards (v Teksasu) omogočajo izračun efektivne poroznosti med 17,0 in 24,4 odstotka, povprečje teh vrednosti pa je blizu poroznosti jedra v vzorcih, ki so bili določeni z geofizikalnimi meritvami $\mathrm{v}$ vrtinah. $\mathrm{V}$ prispevku je predstavljena inovativna metoda za merjenje efektivne poroznosti v vodonosnikih. Zaradi dolgih valovnih dolžin Rayleighjevega valovanja je interdisciplinarni pristop ugoden, saj efektivna poroznost obravnavanega območja vključuje velike kanale ali praznine.

Ključne besede: Rayleighjevo valovanje, Poissonovo razmerje, premiki, tlak v vrtini, Gassmannova enačba.

\footnotetext{
${ }^{1}$ Department of Geophysics, Chenggong Campus, Yunnan University, Kunming, Yunnan 650504 P. R. China, e-mail: guangquanli74@outlook.com

${ }^{2}$ Institute of Geophysics, Earthquake Administration of China, Beijing, China 100081, e-mail: zhangyp@cea-igp.ac.cn

${ }^{3}$ Edwards Aquifer Authority, 900 E Quincy, San Antonio, TX 78215, USA, e-mail: gschindel@edwardsaquifer.org

${ }^{4}$ U.S. Environmental Protection Agency, Center for Public Health and Environmental Assessment (8623R), 1200 Pennsylvania, Ave., N.W., Washington, D.C. 20460, USA, e-mail: field.malcolm@epa.gov

${ }^{5}$ Karlsruhe Institute of Technology (KIT), Institute of Applied Geosciences, Division of Hydrogeology, D-76131 Karlsruhe, Germany, e-mail: nico.goldscheider@kit.edu

* Corresponding author
}

Disclaimer: The views expressed in this paper are solely those of the authors and do not necessarily reflect the views or policies of the U.S. Environmental Protection Agency. Mention of trade names does not constitute endorsement. Declarations of interest: none. 


\section{INTRODUCTION}

\section{SCIENTIFIC BACKGROUND}

Seepage in fluid saturated rocks is driven either by slow fluid pressure wave, or by fast fluid pressure wave (Biot 1956a,b). The former is characterized with active fluid pressure and passive rock stress, while the latter is characterized with active rock stress and passive fluid pressure. A slow fluid pressure wave is precisely diffusive pressure in hydrogeology, and its wave velocity (the velocity of pressure transmission) is very slow. For a fast fluid pressure wave, its wave velocity is very rapid as it is almost synchronous with the (very fast) stress transmission in rock skeleton (dry rock). Stress transmission in rock skeleton is invariably associated with displacements (recorded by seismograms), and the fast transmission is often called seismic waves.

Not all seismic waves can cause fluid pressure in pores to change. Although Biot (1956a,b) stated that the first-arrival body wave, i.e., $\mathrm{P}$ wave (primary and compressional) can cause fluid pressure to change, such changes are very small due to the small amplitude of $\mathrm{P}$ wave. The second-arrival body wave, i.e., $\mathrm{S}$ wave, is featured with shear stress or displacements in rock skeleton. Recall that any fluids cannot sustain a shear stress and they do not contribute to the shear modulus of saturated rocks. S wave generates negligible change in fluid/pore pressure. Similar to $S$ wave, Love surface wave involves pure shear stress and motions, and also incapable of inducing change in pore pressure. Often, it is Rayleigh surface wave that induces fluid pressure to fluctuate significantly.

Typically, a Rayleigh surface wave has a large magnitude and a broad spectrum (multiple components of period), and is thus easy to recognize in seismograms. As with all surface waves, a Rayleigh wave travels at the Earth's surface and its magnitude decreases exponentially with depth, with the effective depth of penetration dependent upon its wavelength components (Lay \& Wallace 1995). Fresh groundwater usually occurs in aquifers at depths less than one kilometer. For undrained rocks that have zero permeability (fluid does not flow between pores), fluid pressure changes synchronously with the confining pressure (Gassmann 1951; Skempton 1954). For seismic waves at frequencies lower than $1 \mathrm{~Hz}$, rocks usually behave as undrained and the two pressures are almost synchronous, but differ from each other in amplitude (Li et al. 2017).

Water wells serve as probes that allow monitoring of changes in hydraulic head. Well head changes usually occur slowly over hours to days (Domenico \& Schwartz
1997) due to rainfall events, nearby pumping, or changes in barometric pressure; these are slow fluid pressure waves. However, when a Rayleigh wave traverses an aquifer, the confining pressure in the consolidated rocks actively compresses and dilates the pore space (because fluid in pores is much more compressible than the solid material), causing fluid pressure to fluctuate with noticeably higher frequencies than routine (slow or diffusive) changes. Therefore, the response of hydraulic head to Rayleigh wave is very easy to discern from normal daily fluctuations (slow fluid pressure wave).

The use of wireline floats and chart recorders is a traditional method for measuring hydraulic head in wells. The Stevens Type F Chart Recorder is an example of a real-time analog method for recording water level fluctuations over time. A change in water level results in the movement of the float which is translated to a paperchart recorder through a wire across a pully. The vertical change in head is recorded by a pen-ink on the paper chart, in which the inked pen draws the well hydrograph on the moving/rotating chart. One limitation is that the high frequency of fluid pressure fluctuations caused by a transient Rayleigh wave is often difficult to resolve in such analog signals, because ink (on the slowly-moving paper chart) smears the high frequencies of the fast fluid pressure wave.

Digital recorders, such as transducers and data loggers, have the potential to record seismic events with much finer resolution. However, most water levels are measured to determine daily or weekly water level trends. Because of data storage issues, transducers and data loggers are commonly set to record water levels every 15 to 30 minutes, which may not provide sufficient resolution to properly evaluate a seismic event.

Water level fluctuations in a well often sustain for several hours due to the free oscillations of the Earth. Therefore, only the amplitude recorded in well hydrographs is reliably utilized in this paper. The raw well hydrographs in this paper were recorded via analogue recorder using The Stevens Type F Chart.

\section{PREVIOUS STUDY}

There are a few previous studies on well head fluctuations induced by seismic waves. Cooper et al. (1965) initiated the first study on how water level in an open well fluctuates in response to $\mathrm{P}$ wave, which depended on well dimensions and aquifer parameters. However, the well head fluctuations with high frequencies are primarily caused by the change of fluid pressure occurring due to 
Rayleigh wave rather than $\mathrm{P}$ wave (having small amplitude).

Liu et al. (1989) observed water level fluctuations induced seismically in the Wali Well, Beijing, China. Shih (2009) and Shih et al. (2013) proposed that storativity of a confined aquifer can be derived from the spectral relationship between well head and vertical displacement of a transient Rayleigh wave. Spitzberg \& Ufrecht (2014) presented hydraulic analysis of a hydro-seismogram acquired from the confined karst aquifer of Stuttgart, Germany. They showed that seismic waves caused distinctive oscillations of well head with characteristics dependent upon the magnitude of the earthquake, local transmissivity and well geometry. However, if the hydraulic connectivity between the well and the surrounding aquifer matrix is good, water head should adequately represent water pressure in the surrounding matrix (Sun et al. 2018). Deresiewicz (1962) proposed that a transient Rayleigh wave in fluid saturated rocks was dissipative due to losses by mode conversion to slow $\mathrm{P}$ wave, which was responsible for the delayed oscillations; this viewpoint was inaccurate because such delayed oscillations are actually induced by free oscillations of the Earth which occur only after seismic waves have reached the antipode of the earthquake epicenter.

\section{PROBLEM IDENTIFICATION}

Strictly speaking, aquifer storativity (specific storage) is defined as $S=\phi \beta_{f}+\beta_{\text {eff }}-\beta_{s}-\phi \beta_{s}$, where $\phi, \beta_{f} \beta_{\text {eff }}$ and $\beta_{s}$ are porosity, compressibility coefficients of water, skeleton and solid material, respectively (Li et al.

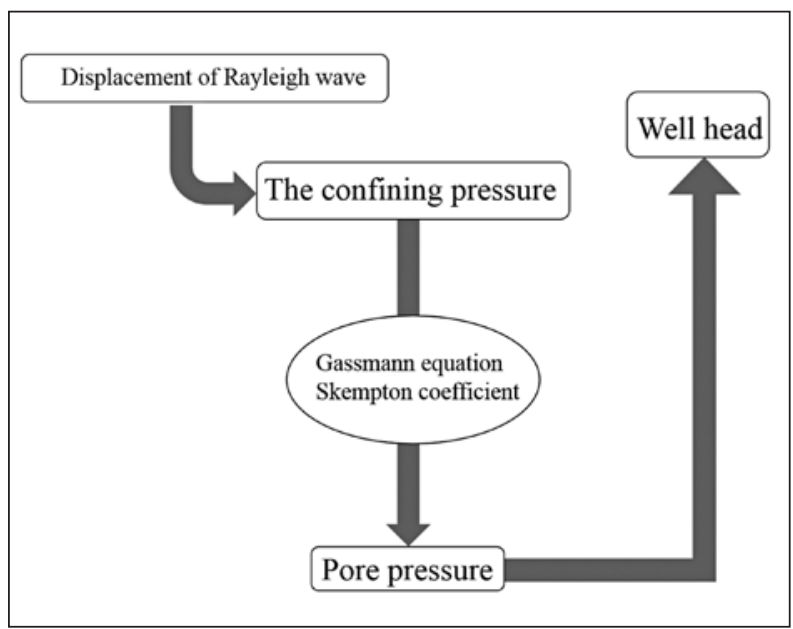

Fig. 1: Diagram which summarizes the essence of the approach in this paper. Rayleigh surface wave (with displacements recorded by seismograms) causes the confining pressure of aquifer rock to change, which then induces the change of pore pressure (via Gassmann equation and Skempton coefficient) that is recorded by well head. 2020a). As a reminder, this expression is slightly more accurate than the one in Domenico \& Schwartz (1997) in considering the compressibility of solid material. Nevertheless, because $\beta_{\text {eff }}$ and $\beta_{s}$ often can be neglected, storativity $S \approx \phi \beta_{f}$. As water compressibility ( $\beta_{f}$ ) is well known (Fine \& Millero 1973), knowledge of porosity can be converted to or from knowledge of storativity.

The definition of storativity in previous studies on aquifer response to Rayleigh wave (Shih 2009; Shih et al. 2013; Folnagy et al. 2013; Sun et al. 2018) required estimation of the aquifer thickness. Actually, as aforementioned, the standard storativity ( $\mathrm{Li}$ et al. 2020a) can be well got via porosity.

Another issue is whether evaluation of the aquifer storativity requires measuring groundwater levels on a scale of seconds (rather than the more typical scale of minutes in most well recorders). For analog hydrographs recorded by the pen-ink on the paper chart, we shall show that amplitude alone (rather than frequencies and sustained duration of a well hydrograph deviation), when used in conjunction with a transient Rayleigh wave on the seismogram, is sufficient for determination of porosity or storativity.

\section{STUDY OBJECTIVE}

While the total porosity includes the entire pore space, effective porosity refers to hydraulically connected pores and voids that aid groundwater flow. The total porosity is invariably higher than effective porosity because the former includes unconnected (inactive) pores and micropores. Traditionally, porosity is often measured in small core samples acquired by drilling. However, karst aquifers are characterized by large conduits (caverns or voids). The problem of scale or heterogeneity is severe when measuring parameters of karst aquifers. Therefore, porosity measured on core samples usually does not represent the actual porosity at the site or aquifer scale.

This paper utilizes a transient Rayleigh wave and its well head response to calculate effective porosity of a karst aquifer at the site scale. Rayleigh wave trains have broad spectra and sample a large volume of rock due to the long wavelength components. As such, the calculated porosity is very likely to represent the actual effective porosity at the site scale.

The essence of our new approach is summarized in Fig. 1. In section 2 we introduce a new elastic theory for combining data from a Rayleigh wave train and the associated well hydrograph to yield effective porosity. The results of applying the theory to the Edwards Aquifer are elucidated in section 3. Section 4 is the discussion. 


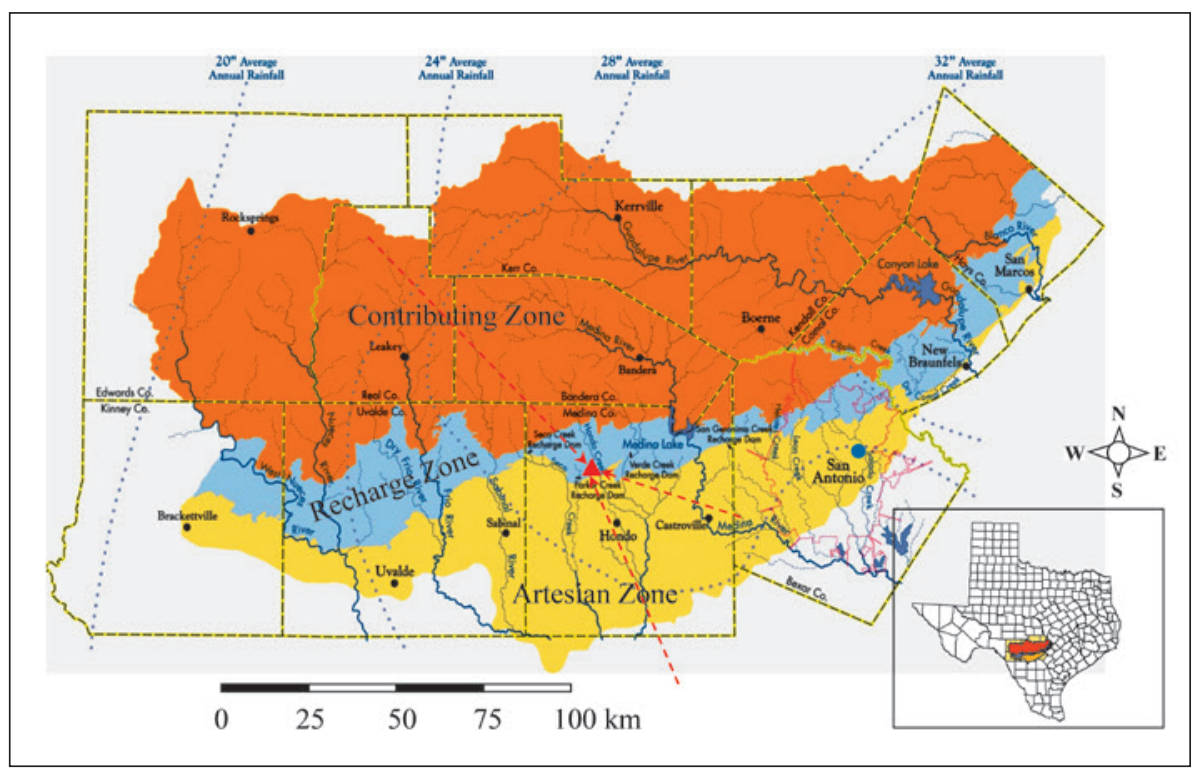

Fig. 2: Hydrogeological map of the Edwards Aquifer, Texas, USA. The contributing zone is Edwards Plateau, from which surface runoffs reach the recharging zone (the unconfined portion of the aquifer) and finally enter the artesian/confined portion of the aquifer. Well J-17 and USARRAY station 633 A are blue dot and red triangle, respectively. The three red dashed arrows represent the wave directions to the station, with the length being half of the major wavelength component.

\section{METHODOLOGY}

The San Antonio segment of the Edwards Aquifer of South-Central Texas is utilized for this study. The Edwards Aquifer is one of the most important and prolific karst aquifers in the United States. It is the primary source of water for municipal and agricultural usage serving more than two million people. The aquifer is more than $250 \mathrm{~km}$ long, $10 \mathrm{~km}$ to $40 \mathrm{~km}$ wide and contained within the Cretaceous Edwards Group limestone. The artesian section of the aquifer ranges from $150 \mathrm{~m}$ to $300 \mathrm{~m}$ thick and can extend to depths of more than 1,000 m below the ground surface (Schindel 2019).

Fig. 2 depicts the hydrogeological map of the Edwards Aquifer. The contributing zone (not recharge zone) is the Edwards Plateau consisting of the Georgetown limestone and the Edwards Group above the Glen Rose Formation (Kresic 2012). Surface runoff from the contributing zone reaches the recharge zone (the unconfined portion of the Edwards Aquifer), and finally enters the confined/artesian zone of the aquifer. Well J-17 is located at Fort Sam Houston in San Antonio and is situated in the confined portion of the Edwards Aquifer.

The elastic model in the Appendix has two assumptions: (1) the rocks are undrained during the passage of a transient Rayleigh wave such that the Gassmann (1951) equation is applicable; (2) the well head adequately represents fluid pressure in the matrix surrounding the well. For assumption (1), dimensional analysis using the Biot theory (Biot 1956a,b) has revealed that the response of saturated rocks to seismic waves is dependent on dimensionless frequency $\Omega=\rho_{f} \frac{k_{D}}{\mu} \omega$ (Li et al. 2020a), where $\rho_{f}, k_{D}, \mu$ and $\omega$ are water density, permeability, water viscosity and angular frequency, respectively. Low frequency $(\omega)$ will cause $\Omega$ to tend to zero. Note that undrained rocks (Darcy permeability $k_{D}=0$ ) results in a vanishing $\Omega$. Comparing these two facts, low frequency is almost equivalent to undrained rocks for the fast fluid pressure wave. Assumption (2) can be justified via proofs by contradiction. If well head did not equal fluid pressure in the surrounding matrix, pressure difference will transfer water between them to achieve pressure balance. For the fast fluid pressure wave, with the increase of frequency, the wavelength will be shorter and the associated pressure gradient will increase to result in a faster seepage (the rocks are less undrained).

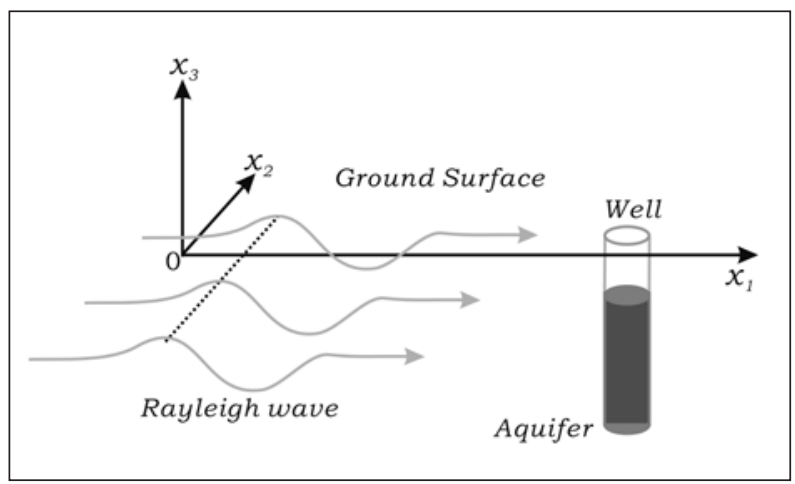

Fig. 3: A schematic Rayleigh wave on the ground surface and the induced head fluctuation in a monitoring well. The Rayleigh wave with a centroid frequency reaches the aquifer to yield the change of groundwater pressure which is measured by the well. 
Whether for the artesian portion or unconfined portion of the aquifer, the limestones can be stressed and displaced by a transient Rayleigh wave, which is reflected in well hydraulic head as depicted in Fig. 3. The radial and vertical displacements of the Rayleigh wave are denoted as $u_{1}$ and $u_{3}$, respectively. Aquifer effective porosity $(\phi)$ is determined by the two displacements via:

$\phi=\frac{\left|u_{1}\right|}{\left|P_{p}\right| T} \frac{2 \pi}{\beta_{f} c}\left(1-c^{2} \hat{\eta}_{\alpha}^{2}\right) \frac{2 \beta^{2}}{c^{2}}$,

$\phi=\frac{\left|u_{3}\right|}{\left|P_{p}\right| T} \frac{2 \pi}{\beta_{f} c} \frac{\left(1-c^{2} \hat{\eta}_{\alpha}^{2}\right)}{\left[c \hat{\eta}_{\alpha}+\frac{1}{2 c \hat{\eta}_{\beta}}\left(\frac{c^{2}}{\beta^{2}}-2\right)\right]}$,

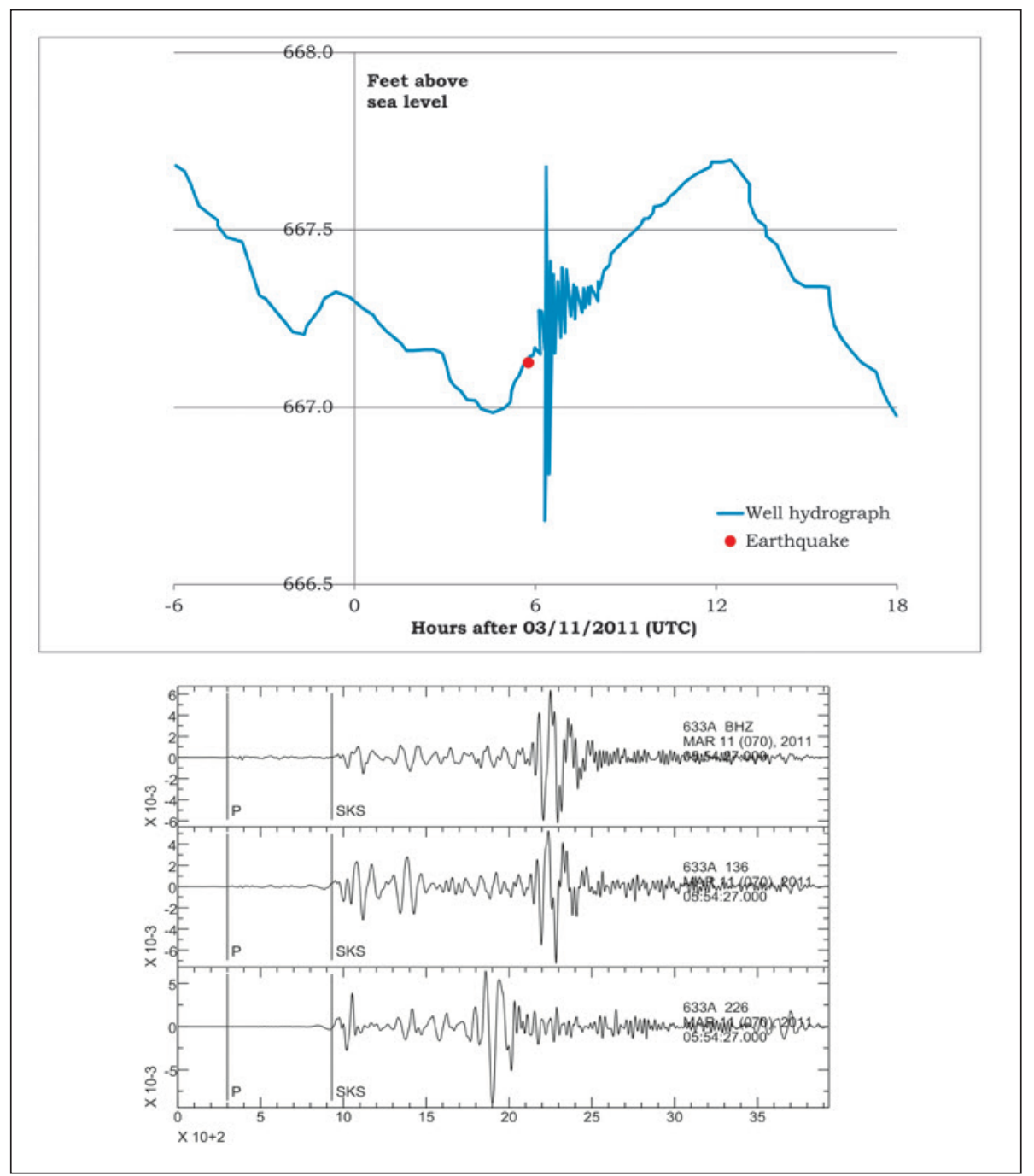

where $P_{p}$ is pore pressure; $T$ is the centroid period of Rayleigh wave; $\alpha, \beta$ and $c$ are velocities of $\mathrm{P}$ wave, $\mathrm{S}$ wave, and Rayleigh wave, respectively ; $\hat{\eta}_{\alpha}=\sqrt{\frac{1}{c^{2}}-\frac{1}{\alpha^{2}}}$, $\hat{\eta}_{\beta}=\sqrt{\frac{1}{c^{2}}-\frac{1}{\beta^{2}}} ;\left|u_{1}\right|,\left|u_{3}\right|$ and $\left|P_{p}\right|$ represent the magnitudes of $u_{1}, u_{3}$ and $P_{p}$, respectively (see Appendix for derivation). Please note that $\phi \beta_{f}$ in Equations (1) and (2) can be converted to the storativity in Shih (2009), Shih et al. (2013), Folnagy et al. (2013) and Sun et al. (2018) if the compressibilities of skeleton and solid material are neglected. Both Equations (1) and (2) are used to calculate effective porosity. Theoretically, porosities obtained via Equations (1) and (2) should be equal. However, variations in estimated seismic velocities and measured Rayleigh wave peak amplitudes or centroid periods may cause the two equations to yield different porosities.

As shown in Fig. 4, Well J-17 recorded water level changes induced by the Ms 9.0 Tohoku (Honshu) earth-

Fig. 4: The upper plot is hydrograph of Well J-17 in the Edwards Aquifer, Texas (from the Edwards Aquifer Authority), showing the response of well head to the Tohoku (Honshu) Ms 9.0 earthquake in Japan on March $11^{\text {th }}$, 2011. The lower plot is seismogram of Station 633A, USARRAY, recording the earthquake. In the lower plot, from top to bottom were $Z$ (vertical), $R$ (radial) and $T$ (transverse) components. The units of time and displacement were seconds and meters, respectively. 


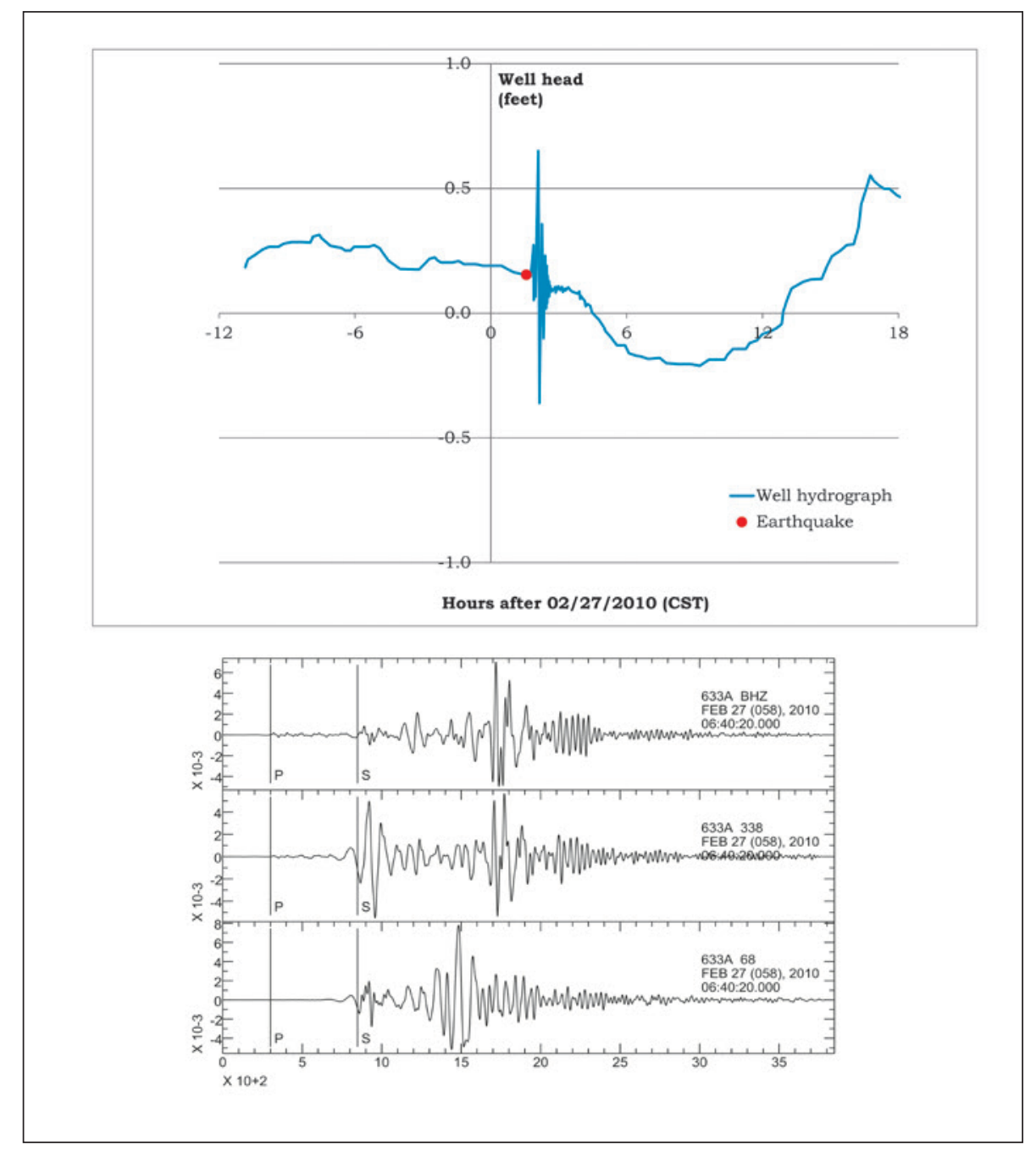

Fig. 5: The upper plot is hydrograph of Well J-17 in the Edwards Aquifer, Texas (from the Edwards Aquifer Authority), showing the response of well head to the Chile Ms 8.8 earthquake on February 27 $7^{\text {th }}$ 2010. The lower plot is seismogram of Station 633A, USARRAY, recording the earthquake. In the lower plot, from top to bottom were $Z$ (vertical), $R$ (radial) and $T$ (transverse) components. The units of time and displacement were seconds and meters, respectively.

quake, which occurred offshore of Japan on March 11,2011 . Seismological station $633 \mathrm{~A}$ (at $99.1766^{\circ} \mathrm{W}$; $29.4591^{\circ} \mathrm{N}$ ) deployed by USARRAY is the nearest station to the well. Three seismograms at the station recorded the Tohoku earthquake, the Chile Ms 8.8 earthquake on February 27, 2010, and the Haiti Ms 7.0 earthquake on
January 12, 2010. As shown in Fig. 4, the Rayleigh wave, after removal of the instrumental response, is on the radial and vertical displacements. The transverse displacement $\left(u_{2}\right)$ shown in Fig. 4 is dominated by Love wave which is incapable of changing pore fluid pressure, as mentioned in Scientific background.

\section{RESULTS}

The dominant Rayleigh wavelengths of the three earthquakes (Honshu Ms 9.0, Chile Ms 8.8, and Haiti Ms 7.0) listed in Tab. 1 were $180 \mathrm{~km}, 129 \mathrm{~km}$, and $84 \mathrm{~km}$, respectively; BAZs (back azimuths) or the angle between North and the reverse of the wave propagation direction (positive clockwise) were 316, 157, and 108 degrees, respectively (Fig. 2). The station is $71 \mathrm{~km}$ from Well J-17. As such, the recorded Rayleigh wave trains should be good approximations of the actual Rayleigh waves at the well. Figs. 5 and 6 show the responses in Well J-17 to the Chile Ms 8.8 and Haiti Ms 7.0 earthquakes, respectively. The corresponding seismograms recorded by Station 633A are also depicted in both figures.

The amplitudes of water level fluctuations induced by the three earthquakes and recorded by the three J-17 well hydrographs are listed in Tab. 1. On the 


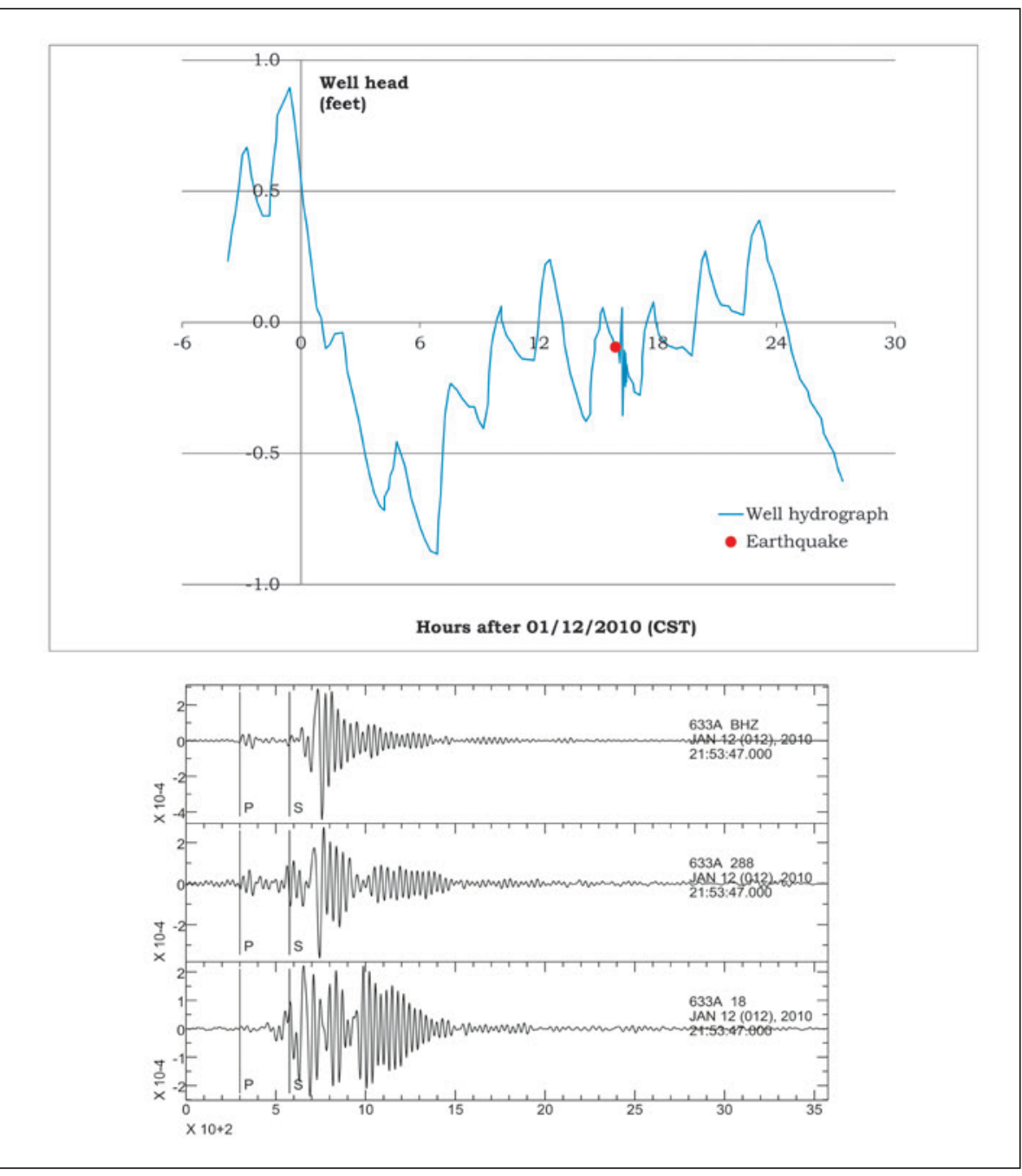

Fig. 6: The upper plot is hydrograph of Well J-17 in the Edwards Aquifer, Texas (from the Edwards Aquifer Authority), showing the response of well head to the Haiti Ms 7.0 earthquake on January $12^{\text {th }}, 2010$. The lower plot is seismogram of Station 633A, USARRAY, recording the earthquake. In the lower plot, from top to bottom were $Z$ (vertical), $R$ (radial) and $T$ (transverse) components. The units of time and displacement were seconds and meters, respectively.

seismograms, the Rayleigh waves are readily identifiable. The largest amplitude is defined as magnitude. The time difference between the greatest peak and the second greatest peak is defined as the centroid period. The magnitudes and centroid periods of the radial and vertical displacements are used along with the amplitudes of the well hydrographs to yield porosity, via Equations (1) and (2), respectively. In our calculations, water compressibility is $4.6 \times 10^{-10} \mathrm{~Pa}^{-1}$ (Fine \& Millero 1973). Saturated limestone has an average S-wave velocity of $2200 \mathrm{~m} \mathrm{~s}^{-1}$ and a Poisson's ratio of 0.26 (recall that the Poisson solid has a Poisson's ratio of 0.25; Wang
2000; Jaeger et al. 2007). In Fig. 7, the radial and vertical components of the three Rayleigh waves are linearly regressed conforming to Equations (1) and (2), eventually yielding porosities of 24.4 percent and 17.0 percent, respectively.

From the three seismograms in Figs. 4-6, the magnitude ratio of the vertical displacement to the radial displacement is approximately 1.2 , which is less than the theoretical value of 1.5 for a Poisson solid. The moment of the vertical displacement maximum is close to that of zero radial displacement, which agrees well with the two displacements having a theoretical phase difference of $\frac{\pi}{2}$

Tab. 1: Water pressure measured on hydrographs for three earthquakes, the centroid period and displacement amplitude on seismograms.

\begin{tabular}{|l|c|c|c|c|c|c|}
\hline Earthquakes & Dates & $\left|P_{p}\right|(\mathrm{Pa})$ & $\mathrm{T}(\mathrm{s})$ & $\left|u_{1}\right|(\mathrm{mm})$ & $\mathrm{T}(\mathrm{s})$ & $\left|u_{3}\right|(\mathrm{mm})$ \\
\hline Honshu Ms 9.0 & $03 / 11 / 2011$ & 1500 & 88.9 & 7.23 & 69.3 & 6.36 \\
\hline Chile Ms 8.8 & $02 / 27 / 2010$ & 1500 & 63.9 & 5.65 & 84.8 & 7.01 \\
\hline Haiti Ms 7.0 & $01 / 12 / 2010$ & 335 & 41.6 & 0.36 & 36.6 & 0.44 \\
\hline
\end{tabular}




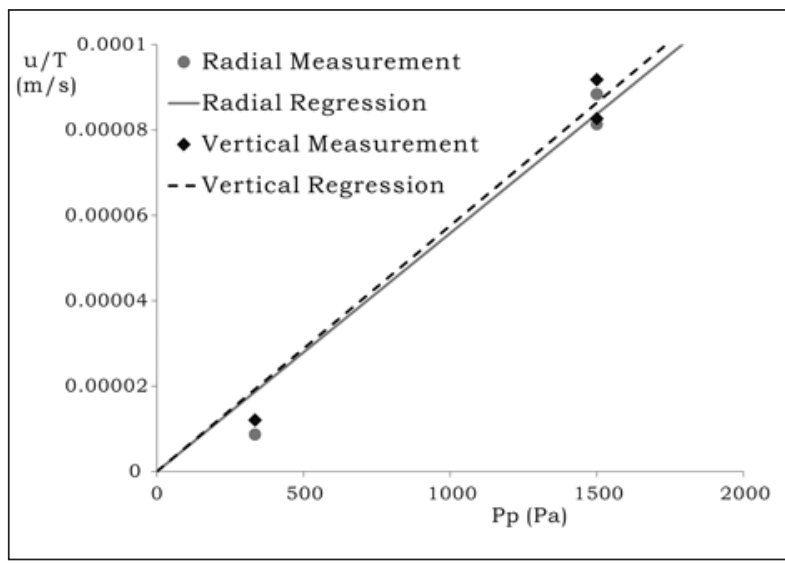

Fig. 7: Amplitude of fluid pressure $\left(P_{p}\right.$ in Well J-17 versus magnitude of the radial and vertical displacements divided by the centroid frequency $\left(\frac{u}{T}\right)$ of the three Rayleigh waves recorded at Station 633A. The slopes regressed by Equations (1) and (2) are 5.58 and $5.7610^{-8} \mathrm{~m} / \mathrm{sPa}$, respectively, yielding effective porosities of 24.4 and 17.0, respectively.

for a Poisson solid (Stein \& Wysession 2003). Rayleigh wave samples the Earth's crust, which may have elastic anisotropy which could contribute to the differences in estimated porosity. In addition, relaxation of the Poisson's ratio does not eliminate the above discrepancy of porosities, suggesting that it arises from complications in the seismic behavior of shallow Earth materials. None- theless, the average between the two porosities turns out to be $20.7 \%$.

Recall that Lagrange velocity is the derivative of displacement with respect to time, such that on a seismogram high frequency in displacement will be amplified in Lagrange velocity while low frequency in displacement will be dampened in the velocity.

Rayleigh wave trains are dispersive (i.e., they have a broad spectrum and the wave velocity is dependent on frequency). However, frequencies far away from the centroid frequency are unimportant as they just minimally affect the peak amplitude of a transient Rayleigh wave. Within a certain band, we can assume its velocity to be constant at the first order of approximation. Our model (Fig. 7) states that:

$\left|P_{p}\right| \propto \omega\left|u_{1}\right|$

In the elastic model, both the Lagrange velocity and displacement of Rayleigh wave are linear with well head. According to Equation (3) high frequencies in a transient Rayleigh wave will be amplified in fluid pressure while low frequencies in the wave will be damped in fluid pressure. This model prediction is inconsistent with the observation that the frequencies on hydrographs are much lower than those on seismograms. In other words, the sustained low-frequency oscillations in well head must come from a different mechanism.

\section{DISCUSSION}

The hydrographs (Figs. 4-6) were recorded by the penink system, the resolution of which was designed for routine groundwater-table measurements, rather than for seismic waves. As such, the analog resolution is insufficient for seismic waves, which is the reason why the frequency of well head fluctuations is not used in this paper. It is necessary that the original records should not be modified and zooming in their time scale would be misleading. This limits our ability to resolve what the hydrographs look like at very fine time scales. Counting the number of peaks and then dividing by duration shows that the frequency of well head oscillations in Figs. 4-6 is much lower than that measured on the seismograms, but is consistent with free oscillations of the Earth.

The sustained durations on the hydrographs are also much longer than those measured on the seismograms, which has not yet been understood previously. Cooper et al. (1965) thought that the resonance of well-water systems is definitely related with pore pressure oscillations in the aquifer. Sun et al. (2018) investigated the hydro- graph of Well X10 (located to the south of Urumqi City in the Xinjiang Autonomous Region in western China), in response to Rayleigh wave. In their study, both the frequency and sustained duration are close between the well hydrograph and Rayleigh wave, suggesting that pore pressure and the confining pressure (associated with well head and Rayleigh wave, respectively) are almost synchronous as Gassmann equation predicted. Why their hydrograph had a short sustained duration and did not observe free oscillations of the Earth is unknown.

Now we calculate the porosity of the confined aquifer in Sun et al. (2018) using a conversion as follows.

$S \rho_{f} g=\phi \beta_{f} \rho_{f} g=S_{s}$

where $S$ and $S_{S}$ are our storativity and the storativity in Sun et al. (2018), respectively; $\rho_{f}$ and $g$ are water density and gravitational acceleration, respectively. Substituting $S_{s} \approx 2 \times 10^{-6} / \mathrm{m}$ (Sun et al. 2018) into (4) yields $\phi \approx 0.43$,which is too high. 
In short periods of time, when the Rayleigh wave train has passed, the rock grains will stop vibrating. The confining pressures of the rocks will become static and accordingly, the changes in fluid pressures due to it via the Gassmann equation will stop. Therefore, the resonant oscillations of water levels in the well arise from two mechanisms: (1) free oscillations of the Earth (standing waves with periods on the order of ten minutes) can cause water level fluctuations; (2) within the well itself (independent of any water transfer between well and matrix), water may slosh (another stationary wave due to the boundary condition of the well wall), causing the float to fluctuate. The second mechanism is less likely as the well radius is small and the float is big.

Whether well completion matters or not depends on the hydraulic connectivity between the well and its surrounding matrix. The well has a diameter of about 10 $\mathrm{cm}$, which is already sufficiently large, and the head loss within the well is small. Moreover, limestone is very permeable, water can easily/quickly transfer between it and the well. For these two reasons, the instantaneous head in the well should be slightly smaller than the in-situ water pressure in the surrounding matrix when waves compress the rock. Consequently, the real porosity might be a little smaller than the calculated porosity, according to Equations (1) and (2).

The Edwards Aquifer is a relatively young karstic aquifer formed in the Cretaceous Edwards Limestone. Porosity obtained for the aquifer from geophysical logs is the total porosity (as in core samples) while porosity obtained from aquifer tests is the effective porosity at the site scale. Based on measurements on core samples by neutron $\operatorname{logs}$, a (conservative) estimate of the total porosity is approximately 20 percent, along with an aquifer thickness of $150 \mathrm{~m}$ (Maclay \& Small 1984). The karst nature of the Edwards Aquifer results in extreme heterogeneity and anisotropy, so that obtaining meaningful porosities from well logs can be highly variable. The effective porosity of representative core samples from the unconfined zone of the Edwards Aquifer at the Lockhill test hole is as high as 17.5 percent (Maclay \& Small 1984). According to Hovorka et al. (1996), the average effective porosity of core samples from the Edwards aquifer is 0.18 (dolomitized subtidal facies beneath stacked tidal-flat cycles have extremely high porosity as much as 45 percent because of dolomite dissolution). In short, the effective and total porosities on core samples are 0.18 and 0.20 , respectively.

The average aquifer porosity achieved by this study represents effective porosity, because unconnected pores/micropores have no hydraulic connection with the well and thus do not contribute to drainage into the well. Our effective porosity appears to be close to the total po- rosity of 0.20 (from core samples which do not include conduits/voids), a little larger than the effective porosity for core samples $(0.18)$. It appears that our approach has detected effective porosity at the site scale, which includes the enhanced secondary porosity represented by conduits or voids that are usually neither encountered nor included in core samples. The long centroid periods of a transient Rayleigh wave sample a large volume of the aquifer near the well, rather than highly localized right at the well.

Ideally, chemical sedimentation would result in low porosity limestone. However, the sedimentation environments are often associated with strong hydrodynamic environments such as tides or waves in shallow seas or lakes, which tend to break up the initially tight carbonate sediments and cause resedimentation of broken grains. In this way, limestone can have a high primary porosity in the matrix. Another cause of high porosity is the numerous small pores that formed by bioclastic (rather than purely chemical) sedimentation. For these two reasons, it is unlikely for ideal chemical sedimentation to exist in field and to produce tight (low porosity) limestone during early stages of lithification.

Wang et al. (2009) investigated the oscillations of water levels in three wells in Taiwan caused by the Wenchuan Ms 7.9 earthquake (Sichuan, China) in 2008. The sampling rate in their hydrographs was $1 \mathrm{~Hz}$. They found that the major water level response (associated with Rayleigh wave) was preceded by small oscillations that occurred concurrently with passage of the $\mathrm{S}$ wave and Love wave. The reason may be that $S$ wave (or Love wave) acceleration or deceleration causes tilting of the water level in the wells (Li et al.2020b). They also thought that the groundwater flow associated with those small oscillations may be strong enough to remove blockages from sediment pores to enhance aquifer permeability and to facilitate the later major responses. However, we think such an effect is very minor because permeability cannot change much due to seismic waves.

For a homogenous rock half space with a Poisson's ratio of 0.26 , Rayleigh wave will manifest a retrograde elliptical particle motion with the magnitude ratio of the vertical displacement to the radial displacement being 1.5. This is the theoretical disadvantage of our model, as the magnitude ratio in the seismograms was approximately 1.2 , suggesting that the subsurface does not consist of one homogenous rock. Also, there are not many datasets available, such that the sample population used in our regression (three data points for each line in Fig. 7) appears to be insufficient. Nevertheless, this paper represents an innovative approach that combines seismological and hydrological data to calculate effective porosity in karst aquifers at the site scale. An interesting tospic of 
future study would be using layered crustal structure to improve the Rayleigh wave modelling.

The major assumption in this paper is that the observed head in the well approximately equals the water pressure in the surrounding aquifer matrix (that on the other hand is almost undrained to validate the elastic model). If the rock is undrained, there will be no transfer of water between well and matrix, although the elastic model is accurate for the matrix. If the rock is well drained, the elastic model will be inaccurate for the matrix, although the observed well head well represents the matrix water pressure. This may be justified by choosing a relatively large volume of matrix the distance of which away from the well is smaller than a certain length. On the whole, the matrix volume can be almost undrained (due to the low frequency or long wavelength of the dominant Raleigh wave), but the limestone matrix neighboring the well is well drained. In this sense, the calculated effective porosity is that of the matrix. Further resolving this challenging issue requires a specific model with hydrogeologic conditions (such as the stratigraphy, confining unit and permeability/transmissivity of the aquifer) as well as the geometry or dimensions of the well, which appears to be an interesting topic for future research.

\section{CONCLUSIONS}

(1) From the radial and vertical displacements of the three recorded Rayleigh wave trains, the new model yielded effective porosities of 24.4 percent and 17.0 percent, respectively, the average of which was higher than the effective porosity $(0.18)$ and close to the total porosity $(0.20)$ from core samples. In this regard, our approach has detected effective porosity at the site scale which includes the enhanced secondary porosity represented by solution conduits or voids.
(2) On the hydrographs, only the amplitudes were used. The frequencies of well head oscillations were much lower than the centroid frequencies of the recorded Rayleigh waves on the seismograms, which may arise from the pen-ink on the paper chart smearing high frequencies. The sustained durations on the hydrographs were much longer than those on the seismograms, and the proposed cause is free oscillations of the Earth with similarly long periods.

\section{ACKNOWLEDGEMENTS}

The research was sponsored in part by the National Natural Science Foundation of China under grant 42064006. The seismograms and instrumental response were downloaded from IRIS. The authors are very thankful for the time and effort that the Editor-in-Chief, Franci Gabrovšek, Co-Editor, Nataša Ravbar, and three anonymous reviewers spent, and their contributing suggestions are deeply appreciated.

\section{REFERENCES}

Biot, M.A., 1956a: Theory of propagation of elastic waves in a fluid-saturated porous solid: I. Lower frequency range.- Journal of the Acoustic Society of America, 28, 168-178. https://doi.org/ 10.1121/1.1908239.

Biot, M.A., 1956b: Theory of propagation of elastic waves in a fluid-saturated porous solid: II. Higher frequency range.- Journal of the Acoustic So- ciety of America, 28, 179-191. https://doi.org/ 10.1121/1.1908241.

Cooper, H., Bredehoeft, J., Papadopulos, I. \& R. Bennett, 1965: The response of well-aquifer system to seismic waves.- Journal of Geophysical Research, 70, 3915-3926. https://doi.org/10.1029/ JZ070i016p03915.

Deresiewicz, H., 1962: The effect of boundaries on wave propagation in a liquid-filled porous-solid: IV. Sur- 
face waves in a half-space.- Bulletin of the Seismological Society of America, 52, 627-638.

Domenico, P.A. \& F.W. Schwartz, 1997: Physical and Chemical Hydrogeology. Wiley, pp. 528, New York.

Fine, R.A. \& F.J. Millero, 1973: Compressibility of water as a function of temperature and pressure.- Journal of Chemical Physics, 59, 5529-5536. https:// doi.org/10.1063/1.1679903.

Folnagy, A., Osiensky, J., Kobayashi, D. \& K. Sprenke, 2013: Specific storage from sparse records of groundwater response to seismic waves.- Journal of Hydrology, 503, 22-28. https://doi.org/10.1016/j. jhydrol.2013.08.037.

Gassmann, F., 1951: Uber die elasticität poröser medien (On the elasticity of porous media).- Vierteljahrsschrift der Naturforschenden Gesllschaft in Zürich, 96, 1-23.

Hovorka, S.D., Dutton, A.R., Ruppel, S.C. \& J.S. Yeh, 1996: Edwards aquifer ground-water resources: Geologic controls on porosity development in platform carbonates, South Texas.- Report of Investigations No. 238, Bureau of Economic Geology, The University of Texas at Austin, pp.75, Austin. https:// doi.org/10.23867/RI0238D.

Jaeger, J., Cook, N. \& R. Zimmerman, 2007: Fundamentals of Rock Mechanics. Wiley-Blackwell, pp. 488, New York.

Kresic, N., 2012: Water in Karst - Management, Vulnerability, and Restoration. McGraw-Hill, pp. 736, New York.

Lay, T. \& T. Wallace, 1995: Modern Global Seismology. Academic Press, pp. 536, New York.

Li, G., Zhang, P. \& J. Sun, 2017: A new model describing the interaction between fluid pressure wave in pores and $\mathrm{P}$ wave in rock matrix.- Geophysics, 82, MR105-MR109. https://doi.org/10.1190/geo20160285.1 .

Li, G., Liu, K. \& X. Li, 2020a: Comparison of fluid pressure wave between Biot theory and storativity equation.- Geofluids, Article ID 8820296. https:// doi.org/10.1155/2020/8820296.

Li, G., Liu, S. \& B. Wang, 2020b: A new double porosity model of $\mathrm{S}$ wave attenuation due to acceleration.Geophysical Prospecting, under review.

Liu, L., Roeloffs, E. \& X. Zheng, 1989: Seismically induced water level fluctuations in the Wali Well, Beijing, China.- Journal of Geophysical Research,
94(B7), 9453-9462. https://doi.org/10.1029/ JB094iB07p09453.

Maclay, R.W. \& T.A. Small, 1984: Carbonate geology and hydrology of the Edwards Aquifer in the San Antonio area, Texas.- USGS Open File Report 83537. Https://doi.org/10.3133/ofr83537.

Schindel, G.M., 2019: Genesis of the Edwards (Balcones fault zone) Aquifer.- In: J.M. Sharp, R.T. Green \& G.M. Schindel (eds.) The Edwards Aquifer: The Past, Present, and Future of a Vital Water Resource. Geological Society of America Memoir 215, pp. 9-18. https://doi.org/10.1130/2019.1215(02).

Shih, D., 2009: Storage in confined aquifer: Spectral analysis of groundwater responses to seismic Rayleigh waves.- Journal of Hydrology, 374, 83-91. Https://doi.org/10.1016/j.jhydrol.2009.06.002.

Shih, D., Wu, Y. \& C. Chang, 2013: Significant coherence for groundwater and Rayleigh waves: Evidence in spectral response of groundwater level in Taiwan using 2011 Tohoku Earthquake, Japan.- Journal of Hydrology, 486, 57-70. https://doi.org/10.1016/j. jhydrol.2013.01.013.

Skempton, A.W., 1954: The pore pressure coefficients A and B.- Geotechnique, 4, 143-147. https://doi. org/10.1680/geot.1954.4.4.143.

Stein, S. \& M. Wysession, 2003: An Introduction to Seismology, Earthquakes, and Earth Structure. Blackwell, pp. 498, New York.

Spitzberg, S. \& W. Ufrecht, 2014: Hydraulic characterization of a karst aquifer in an urban environment focusing on erratic pressure signals.- Grundwasser, 19, 17-27, https://doi.org/10.1007/s00767-013$0242-4$

Sun, X., Xiang, Y. \& Z. Shi, 2018: Estimating the hydraulic parameters of a confined aquifer based on the response of groundwater levels to seismic Rayleigh waves.- Geophysical Journal International, 213 (2), 919-930. https://doi.org/10.1093/gji/ggy036.

Wang, H.F., 2000: Theory of Linear Poroelasticity - with Applications to Geomechanics and Hydrogeology. Princeton University Press, pp. 304, Princeton.

Wang, C., Chia, Y., Wang, P. \& D. Dreger, 2009: Role of $\mathrm{S}$ waves and Love waves in coseismic permeability enhancement.- Geophysical Research Letters, 36, L09404. https://doi.org/10.1029/2009GL037330. 


\section{APPENDIX: ELASTIC MODEL OF RAYLEIGH WAVE CHANGING PORE PRESSURE}

The radial and vertical displacements of a Rayleigh wave (denoted as $u_{1}$ and $u_{3}$, respectively) are as follows (Lay \& Wallace 1995; Stein \& Wysession 2003).

$$
\begin{aligned}
& u_{1}=-A k\left[e^{-c \hat{\eta}_{\alpha} k x_{3}}+\frac{1}{2}\left(\frac{c^{2}}{\beta^{2}}-2\right) e^{-c \hat{\eta}_{\beta} k x_{3}}\right] \sin \left(k x_{1}-\omega t\right), \\
& u_{3}=-A k\left[c \hat{\eta}_{\alpha} e^{-c \hat{\eta}_{\alpha} k x_{3}}+\frac{1}{2 c \hat{\eta}_{\beta}}\left(\frac{c^{2}}{\beta^{2}}-2\right) e^{-c \hat{\eta}_{\beta} k x_{3}}\right] \cos \left(k x_{1}-\omega t\right),
\end{aligned}
$$

where $A$ is magnitude, $k$ is wavenumber, $\omega$ is angular frequency, $t$ is time, $x_{1}$ and $x_{3}$ represent the radial and vertical Cartesian coordinates, respectively, $\alpha, \beta$ and $c$ are velocities of $\mathrm{P}$ wave, $\mathrm{S}$ wave and Rayleigh wave, respectively, $\hat{\eta}_{\alpha}=\sqrt{\frac{1}{c^{2}}-\frac{1}{\alpha^{2}}}, \hat{\eta}_{\beta}=\sqrt{\frac{1}{c^{2}}-\frac{1}{\beta^{2}}}$.

The confining pressure $(P)$ is calculated via the strain volume $(\theta)$ as follows.

$$
\frac{P}{K}=\theta=\frac{\partial u_{1}}{\partial x_{1}}+\frac{\partial u_{3}}{\partial x_{3}}=-A k^{2}\left(1-c^{2} \hat{\eta}_{\alpha}^{2}\right) e^{-c \hat{\eta}_{\alpha} k x_{3}} \cos \left(k x_{1}-\omega t\right)
$$

where $K$ is the bulk module of the saturated rock (the reciprocal of the compressibility coefficient of the saturated rock).

At the ground surface, $x_{3}=0$, and Equations (A1-A3) yield:

$$
\begin{aligned}
& u_{1}=-A k \frac{c^{2}}{2 \beta^{2}} \sin \left(k x_{1}-\omega t\right), \\
& u_{3}=-A k\left[c \hat{\eta}_{\alpha}+\frac{1}{2 c \hat{\eta}_{\beta}}\left(\frac{c^{2}}{\beta^{2}}-2\right)\right] \cos \left(k x_{1}-\omega t\right), \\
& \frac{P}{K}=-A k^{2}\left(1-c^{2} \hat{\eta}_{\alpha}^{2}\right) \cos \left(k x_{1}-\omega t\right) .
\end{aligned}
$$

Combining (A4-A5) with (A6) yields:

$$
\begin{aligned}
& \frac{|P|}{\left|u_{1}\right| K}=k\left(1-c^{2} \hat{\eta}_{\alpha}^{2}\right) \frac{2 \beta^{2}}{c^{2}}, \\
& \frac{|P|}{\left|u_{3}\right| K}=\frac{k\left(1-c^{2} \hat{\eta}_{\alpha}^{2}\right)}{c \hat{\eta}_{\alpha}+\frac{1}{2 c \hat{\eta}_{\beta}}\left(\frac{c^{2}}{\beta^{2}}-2\right)},
\end{aligned}
$$

respectively, where || defines the $1_{1}$ norm. 
Because the compressibility coefficient of rock's solid material is tiny, the confining pressure $(P)$ is related to fluid pressure $\left(P_{p}\right)$ via Skempton (1954) coefficient as follows.

$\frac{P}{P_{p}}=\frac{\phi \beta_{f}+\beta_{e f f}}{\beta_{e f f}}$

where $\phi$ is porosity, and $\beta_{f}$ and $\beta_{\text {eff }}$ are compressibility coefficients of fluid and skeleton (dry rock), respectively. Gassmann (1951) equation states the relation between $\phi, \beta_{\text {eff }}, \beta_{f}$ and $K$ as follows.

$\frac{\phi \beta_{f}+\beta_{\text {eff }}}{\beta_{\text {eff }}}=\phi \beta_{f} K$,

in which the compressibility of rock's solid material has been well neglected.

Substituting (A9) into (A7) and incorporating (A10) yield:

$\phi=\frac{\left|u_{1}\right|}{\left|P_{p}\right| \beta_{f}} \frac{2 \pi}{T c}\left(1-c^{2} \hat{\eta}_{\alpha}^{2}\right) \frac{2 \beta^{2}}{c^{2}}$,

where $T$ is the centroid period of the Rayleigh wave. Please note that wavenumber $k=\frac{2 \pi}{c T}$.
Similarly, for the vertical displacement, we get

$\phi=\frac{\left|u_{3}\right|}{\left|P_{p}\right| \beta_{f}} \frac{2 \pi}{T c} \frac{\left(1-c^{2} \hat{\eta}_{\alpha}^{2}\right)}{c \hat{\eta}_{\alpha}+\frac{1}{2 c \hat{\eta}_{\beta}}\left(\frac{c^{2}}{\beta^{2}}-2\right)}$.

The major assumption of the above elastic model is that the aquifer matrix is undrained (no water is allowed to transfer between pores). Nevertheless, dimensional analysis (Li et al. 2020a) has shown that a low frequency $(\omega \rightarrow 0)$ is almost equivalent to undrained rock (Darcy permeability $k_{D} \rightarrow 0$ ) for the fast fluid pressure wave. Therefore, the elastic model is accurate at the first order of approximation. 